\title{
Burden of nosocomial rotavirus gastroenteritis in the paediatric population in Slovakia
}

\author{
M Stefkovicova ${ }^{1 *}$, Z Kristufkova $^{2}$, J Brnova ${ }^{3}$ \\ From 3rd International Conference on Prevention and Infection Control (ICPIC 2015) \\ Geneva, Switzerland. 16-19 June 2015
}

\section{Introduction}

Rotavirus gastroenteritis (RVGE) is most common nosocomial infection in paediatric department worldwide.

\section{Objectives}

The aim of this study was assessed prevalence of nosocomial RVGE in children younger than 5 years in Slovakia during the last five years surveillance period.

\section{Methods}

We assessed burden of hospital-acquired RVGE in Slovakia from national epidemiologic surveillance systems (EPIS) in period 2009 to 2013. Nosocomial RVGE was defined i) when the child was admitted with a diagnosis other than gastroenteritis ii) when the first symptoms of RVGE appeared not earlier than $24 \mathrm{~h}$ after admission iii) when the family reported no signs of diarrhoeal diseases iii) when the child was re-hospitalized at the children's department within 3 days (incubation period for RVGE) with symptoms of gastroenteritis after the first admission iiii) when RVGE was confirmed by laboratory testing (ELISA or rapid immunochromatographic test).

\section{Results}

RVGE was clinically and laboratory confirmed in 11967 in children younger than 5 years. Each year were reported on average $2393 \pm 576(1803-3222)$ cases, of them $78,9 \%$ required hospitalisation. According the criteria for nosocomial infection totally $1533(12,8 \%)$ cases were nosocomial RVGE. Additionally, in Slovakia immunisation of infants with rotavirus vaccines has been implemented since 2006 and vaccination coverage reached $17,5 \%$ in year 2013.

'School of Health Care, Alexander Dubcek University of Trencin, Trencin, Slovenia

Full list of author information is available at the end of the article

\section{Conclusion}

Nosocomial RVGE represents a serious epidemiological and economical problem in Slovakia. Mandatory vaccination covered by health insurance and better practise in hospital hygiene, especially improvement in compliance to multimodal strategy for hand hygiene, could reduce prevalence of nosocomial RVGE on paediatric department in Slovakia in the next decades.

\section{Disclosure of interest}

None declared.

\section{Authors' details}

'School of Health Care, Alexander Dubcek University of Trencin, Trencin, Slovenia. ${ }^{2}$ School of Public Health, Slovak Medical University, Bratislava, Slovenia. ${ }^{3}$ Department of Laboratory Medicine, School of Health Sciences and Social Work, Trnava University, Trnava, Slovakia.

Published: 16 June 2015

doi:10.1186/2047-2994-4-S1-P226

Cite this article as: Stefkovicova et al:: Burden of nosocomial rotavirus gastroenteritis in the paediatric population in Slovakia. Antimicrobial Resistance and Infection Control 2015 4(Suppl 1):P226.

Submit your next manuscript to BioMed Central and take full advantage of:

- Convenient online submission

- Thorough peer review

- No space constraints or color figure charges

- Immediate publication on acceptance

- Inclusion in PubMed, CAS, Scopus and Google Scholar

- Research which is freely available for redistribution

Submit your manuscript at www.biomedcentral.com/submit
( Biomed Central 